\title{
An indigenous psychology perspective on psychosocial support in Southern Africa as collective, networking and pragmatic support
}

Ebersöhn, L., Loots, T., Malan-Van Rooyen, M., Mampane, R., Nthontho, M., Omidire, F., \& Sefotho, M.

\begin{abstract}
This comparative case study seeks to describe the traditional African psychosocial support practices used in postcolonial Southern Africa. We use an indigenous psychology theory (relationship-resourced resilience) as a theoretical lens to understand and supplement dominant Western discourses on psychosocial support. Seven Southern African communities with high need and indigenous belief systems were conveniently sampled. Participatory reflection and action (PRA) methods were used to generate data from a snowball sample of individuals with a dominant African home language, and who demonstrated significant vulnerability. $(n=430$ : elders=240; youth=190; men=150 and women=280). Focus groups were audio-recorded and their speech transcribed. Observation data were documented in photographs. After incase and cross-case analysis, we found that psychosocial support was collective, pragmatic and capitalised on networking. The psychosocial support strategies expand insight into the indigenous psychology theory on collective resilience. The intentional description of robust non-Western psychosocial support practices, continued to be used by elders and young people in rural and urban spaces in Southern Africa establishes that endemic practices exist in lieu of policy-level support to provide much-need services given frequent and intense need. Knowledge of the way in which psychosocial support is commonly provided affords an opportunity to graft development initiatives onto that which has withstood adversity, rather than reimagining interventions.
\end{abstract}

\section{Keywords}

Southern Africa, indigenous psychology, psychosocial support, social support, networking, collective resilience

\section{Introduction and rationale}

Contextual vulnerability, synonymous with postcolonial societies, imply increased need for mental health services to counter the presence of high levels of anxiety, depression, and externalised behaviours. On the 
other hand the formal provision of mental health services is neglected because of structural disparity (Eaton, J., McCay, L., Semrau, M. et al., 2011) in marginalised communities. In Southern Africa, marginalised communities are often challenged by high risk and high need, leading to multiple health challenges requiring intervention which often takes the form of non-governmental programmes or citizens providing reciprocal informal psychosocial support (Hanlon et al., 2014). In addition to the challenges of accessibility, the existing mental health services are mostly rooted in Western-dominated discourses about psychosocial support (Eggenberger, 2012) which do not account for the existing traditional psychosocial support (Ntuli, 2002) that are rooted in Indigenous Knowledge Systems (IKS), originating in a unique context and culture (Odora Hoppers, 2009). When Western perceptions of psychosocial support are applied to non-Western communities while ignoring IKS-driven understanding of support practices, these communities might question their own identity, world-views and practices (Pickren, 2009).

Postcolonial societies, like those in Southern Africa, differ from European societies like England. Even after the advent of democracy the differences are overtly visible in that power structures, and consequently the distribution of resources, continue often to favour minority groups. In addition, although non-Western groups may be dominant population clusters their languages (and one may argue their worldviews) probably remain silenced in education, policy and commerce. Therefore decolonising would imply intentionally deliberating how non-Western and dominant worldviews can be acknowledged and mobilised to address hardship that exist because of colonisation and potentially enhancing social cohesion that includes multiple (and especially dominant) worldviews in that given society.

Understanding, acknowledging and mobilising IKS and practices are essential so that people can cope with adversity and high risk (Owusu-Ansah \& Mji, 2013). Involving communities and considering their cultural practices enables insider agency by acknowledging those affected in the decisions that affect them (Briggs, 2005).

Southern African knowledge systems are largely missing from psychosocial science. We use relationship-resourced resilience (RRR) as an indigenous psychology theoretical lens to supplement dominant Western discourses about psychosocial support interventions with indigenous knowledge. RRR argues that when individuals use relationships as a way to access and mobilise resources an enabling ecology is formed to promote positive adjustment. Resilience can therefore occur as collective, rather than individual processes (Ebersöhn, 2012a). Theoretically, RRR is grounded in findings from a ten year school- 
based intervention studies in rural and urban challenged settings in three South African provinces (Ebersöhn, 2012a). RRR explains how collective resilience is supported by flocking (rather than fight, flight, freeze or faint) (Schmidt, Richey, Zvolensky \& Maner, 2008) responses to adversity. Flocking behaviour was evident in teacher responses to address on-going risk, and consequent needs, of children, teachers themselves and family-systems made vulnerable due to structural disparity (Ebersöhn, 2013). Flocking denotes instrumental social support for resource management with the caveat of support for collective gain. Flocking manifests as civic agency to address communal hardship and to support communal positive development and wellbeing outcomes.

The aim of our study was to be intentional in highlighting non-Western psychosocial support practices which have been used traditionally in postcolonial Southern Africa for two reasons. On the one hand the theoretical assumption is that such endemic practices exist in lieu of policy-level support to provide services and merit systematic inquiry. On the other hand, knowledge of the way in which collective resilience is commonly used provides an opportunity to graft development initiatives onto that which has withstood adversity, rather than re-imagining interventions. Accordingly, the pressing question in this article is: how can knowledge of Southern African indigenous responses to adversity inform psychosocial interventions in settings with predominantly African populations?

\section{Psychosocial support needs and services in postcolonial, emerging economies: The case of Southern}

\section{Africa}

Hlalele (2012) states that psychosocial support is a process which focuses on the psychological, emotional, spiritual and social development of individuals toward achieving positive human development. It encompasses the psychological and social services essential for achieving a state of health and wellbeing as "a state of complete physical, mental and social wellbeing and not merely the absence of disease or infirmity" (WHO, 2006: 1).

Psychosocial support occupies a critical space in postcolonial emerging economies due to the characteristically high structural disparity. While struggling to achieve the 2015 health millennium developmental goals (United Nations, 2015), marginalised and poor communities (United Nations, 2015) in low- and medium-income countries (African Development Bank Group, 2011) have to contend with limited resources and fractured service delivery. In Southern Africa this means the majority of the 
population faces chronic poverty and related adversities and is at greater risk of poorer mental health and lower levels of overall wellbeing (Bongani, Mayosi \& Benatar, 2014). Essential psychosocial support services depend on limited government health and social services, non-governmental agencies (Rosenberg, Hartwig \& Merson, 2008) and cultural practices, knowledge and customs for the psychosocial support needed (Kayombo, Mbwambo \& Massila, 2005).

Consequently, although high vulnerability to poorer mental health and wellbeing calls for accessible services such as psychosocial interventions, this remains a challenge in South Africa (Williams et al., 2008) for reasons of affordability, geographical accessibility and cultural relevancy. Attempts to make psychosocial interventions more accessible by addressing cultural relevancy are still inadequate, however, because Western-dominated psychological services embedded in Western traditions and understanding of psychological wellbeing are indiscriminately applied to non-Western people (Marsella, 2009). South African psychology scholars have expressed concern about applying Western psychological theories to African contexts as these may result in irrelevant and unequally distributed psychological services (Ebersöhn, 2012b).

Non-Western populations might feel misunderstood because the assumptions and expectations of health and wellbeing differ from those in Western cultures (Gone, 2010). Moreover, a limited understanding of local customs, language and norms adds to the existing barriers, further marginalising non-Western populations and limiting access to relevant mental health services (Westerman, 2010). NonWesterndominant contexts require psychological methods embedded in the local language, history and culture (Pickren, 2009).

\section{Indigenous knowledge and wellbeing (psychosocial) interventions}

The need to create a psychology relevant to non-Western contexts, such as those in South Africa, is evident in the greater attention being paid to Indigenous Psychology (IP) (Allwood \& Berry, 2006). IP questions knowledge hegemony and focuses on the cultural context in which psychological phenomena occur to help people promote wellbeing by dealing with problems in a culturally relevant and efficient manner through the use of alternative ways of knowing (Odora Hoppers, 2008). 
According to Maotane (2012) the development of indigenous psychology has four developmental stages. The Pioneer period, as the first phase, represents the acknowledgement by intellectual pioneers that psychology (including mental health services) is relevant to a certain culture

(Maotane, 2012). The second phase is referred to as the introductory and modelling level during which Western psychology is introduced to a culture, followed by the third phase namely indigenisation. South Africa is still in the indigenisation phase, which refers to adaptive mainstream psychology theories, concepts and methods before applying them to South African cultures (Kim, 2000). However, merely adapting the mainstream concepts does not account for the complexity of the psychological phenomena arising from non-Western contexts. The integration level is recognised as the fourth level during which an indigenous psychology is created based on a context's specific indigenous knowledge systems (Kim, 2000).

In order to move beyond indigenisation, South African scholars in the field of psychology ought to access and document IKS to contribute to new concepts, theories and intervention strategies that would resonate with indigenous peoples' values and ways of knowing (Chilisa, 2012). The global reign of western psychology as well as the effect of colonialism and the apartheid era largely accounts for inequality in mental health services (Coovadia, Jewkes, Barron, Sanders \& Mclntyre, 2009) and undocumented indigenous knowledge systems. However several recent attempts in mental health research (Ebersöhn, 2012; Maree, Ebersöhn \& Molepo, 2006; Odendaal \& Moletsane, 2011) show a movement in steering South Africa towards the fourth phase of indigenous psychology development.

\section{Relationship-resourced resilience (RRR) and flocking as a Southern African response to adversity}

Ebersöhn's (2013) RRR is an indigenous psychology theory that explains collective resilience. An indigenous pathway to secure collective resilience is flocking, a collective, socio-cultural response to significant risk. Flocking uses instrumental social support to use available relationships as a social mechanism for resource management. Relationships serve conduits to access, mobilise and sustain the distribution of available resources to people in need of support. RRR explains flocking as a pathway for pockets of individuals to collaborate in order to create support (enablement) in a setting saturated with constraints. The network of flocking support creates a climate where connected individuals can buffer themselves and others against continued challenges in their environment - hence promoting collective resilience (better than expected outcomes for many. 
The RRR indigenous psychology theory explains how Southern African cultures have informed, and continue to inform, collective human response to chronic and cumulative adversity (i.e. poverty, rurality, inequality) in Southern Africa (ibid). RRR explains the African cultural pathways that people use to act collectively to both (i) address hardship, and (ii) attain (collective) wellbeing (ibid). RRR is therefore grafted onto African cultural beliefs of social connectedness, as well as people's connectedness to nature and their spiritual connectedness to ancestors (Ebersöhn, 2015). RRR treats relationships as a fulcrum for adaptation and indicates that socio-emotional competence is essential for tapping into social responses (Ebersöhn, 2016).

As collective resilience flocking is defined as an African resilience pathway where relationships, as collective resilience-promoting networks, use shared, available resources in collaborative adaptive processes to address joint contextual adversity and promote communal positive outcomes. Social capital for collective gain is essential in flocking actions to alleviating hardship. Communal positive outcomes of flocking include relational pathways for collective livelihood activities; spirituality activities; as well as health, leisure and self-actualisation (learning and development) (De Gouveia, 2015).

RRR argues that flocking is robust - it continues to be used in Southern African communities with prominent traditional values (Ebersöhn, Sefotho, Mampane et al. (2014). Flocking leverages African cultural beliefs about communal capital (social, cultural, financial, capability, etc.). It follows from this belief that the available collective resources constitute a pool from which people can draw, in order to develop plans to provide collective assistance.

\section{Methodology}

\section{Case selection and participants sampled}

In this comparative case study (Zartman, 2012), we used Participatory Reflection and Action (PRA) (Chambers, 2013) to generate data on non-Western psychosocial support practices which are traditionally supported, without outsider investment, in challenging Southern Africa contexts.

Image 1 shows the seven $(n=7)$ conveniently sampled sites in four Southern African countries (Lesotho (rural), Namibia (urban), Swaziland (rural), and the following provinces in South Africa: Eastern Cape (urban), Gauteng (urban), Limpopo (peri-urban) and North West (peri-urban). The sample has an oversupply of cases in South Africa, and excludes the IKS perspectives of residents in nonchallenging 
settings. The intervention sites of the Nelson Mandela Children's Fund ${ }^{1}$ are characterised by high adversity requiring care and support intervention. Characteristic adversities include poverty; unemployment; high HIV/Aids prevalence; and the limited provision of and access to quality health, education, electricity, sanitation and transport services.

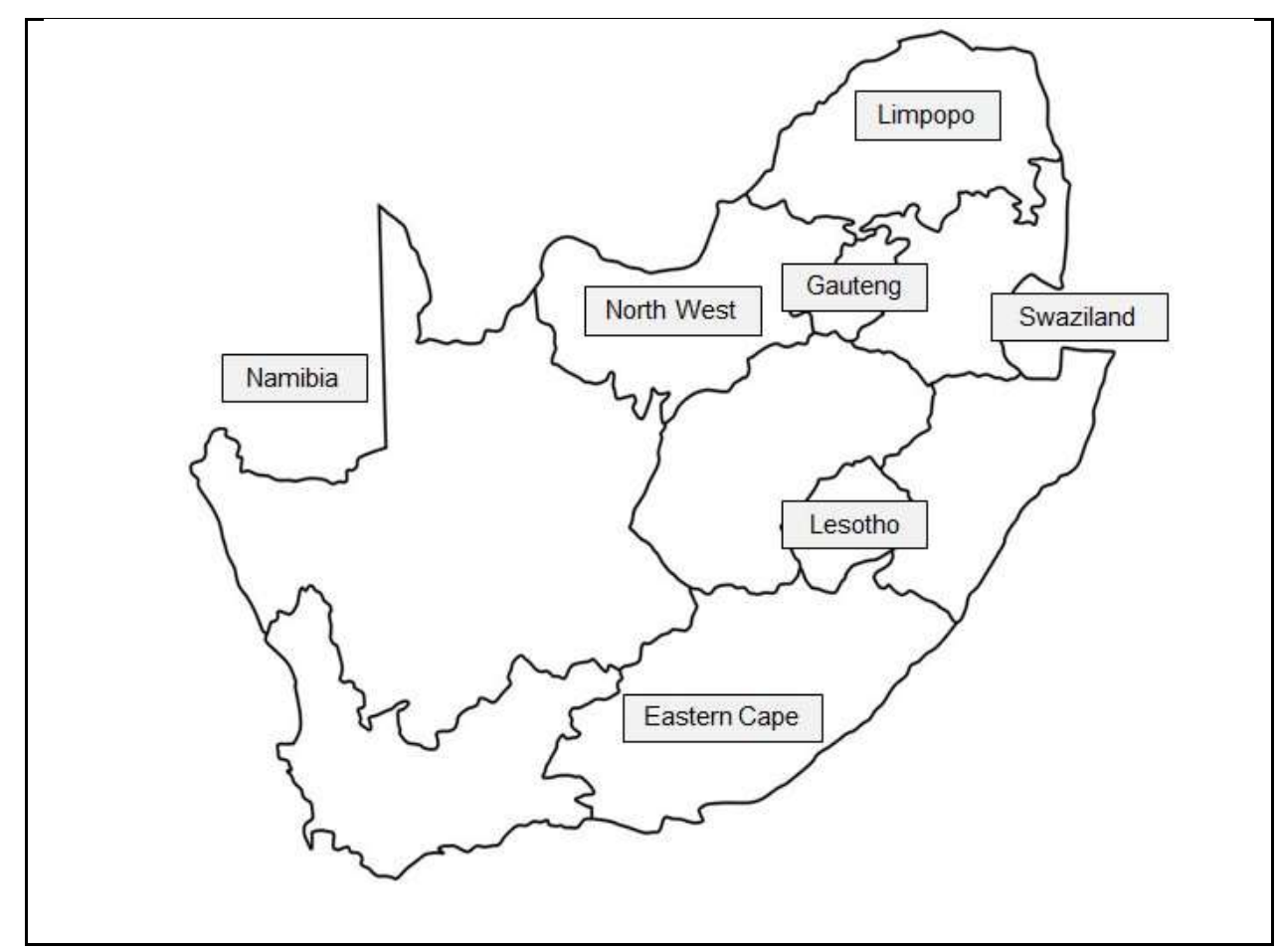

Image 1: Sampled sitesin Southern Africa.

Snowball sampling was used in the selected challenging contexts to draw a sample of residents with predominantly African world-views (indigenous home-language). Snowball sampling entailed accessing the existing social networks by means of relationships with regional non-government intervention coordinators and partners of Nelson Mandela Children's Fund, and their relationship with local elders. The participation of individuals could be invited if their home language was an indigenous language and they were known to be vulnerable.

Highly vulnerable young people under the age of 18 years were excluded, because of the already high vulnerability status of the context. Exposer to complex social and medical problems makes children to be highly vulnerable (Bunkers \& Andrews, 2017; Vanderbilt et al., 2013). When compared to their peers,

\footnotetext{
${ }^{1}$ Regional partners who assisted by providing access to research sites in the reported study include the Red Cross, Lesotho; Save the Children, Swaziland; Church Alliance for Orphans, Namibia; Albertina Sisulu Special School, Gauteng; Diaz Primary School, Eastern Cape; Sepanapudi Traditional Authority, Limpopo; Emmang Basadi Advocacy and Lobby Organisation, North West Province.
} 
highly vulnerable children have more exposure to multiple adversity in their context of development. For this article, highly vulnerable includes any physical or mental handicap or any other long-term difficulty that would make it difficult for the child to participate in the study; illness, either HIV or other major illness; and emotional or psychological problems. It is for these reasons that we considered people above the age of 18 years to be suitable for participation. It was our belief that their long life experiences have gained them valuable indigenous skills such as how to better communicate and guide the deserving people than young and vulnerable children would do. Furthermore, due to their high vulnerability status, some children would need more intensive individualized attention than the researchers could typically provide. Finally, obtaining consent from parents as well as assent letters from children would also affect the study period negatively.

No prior testing was conducted to check the suitability of participants but the researchers relied on the selection done by coordinators in the regional partners who were privileged to have information of the targeted populace due to their relationship and background knowledge of them. This selection was not done until the researchers gave full assurance of confidentiality and information anonymity about the participants. Ethical approval was first obtained from the Faculty Ethics Committee and related designated authorities in concerned regions. Consent forms, developed in English and indigenous homelanguage in a particular region were given to participants to be signed by them. The form gave detailed information about the research. The participants were allowed to participate in the study only after the form was signed. All the participants were informed about the study and its goals as well as the protection of their privacy and sensitivity. Participation in the research was voluntary and participants were informed of their right to terminate their participation.

Table 1 gives an overview of the sampled participants by region, age and gender. In order to generate age-related indigenous views, the participants in every region divided themselves into groups, i.e. groups of older women $(\mathrm{OW})$, older men $(\mathrm{OM})$, younger women (YM) or younger men (YM). Lesotho, the North West and Eastern Cape provinces in South Africa were under-represented. The groups of older men and younger men had fewer members than the female counterpart groups. Under representation in the above areas could be attributed to the ethical decision of voluntary participation. In all the research sites, regional coordinators of Nelson Mandela Children's Fund were instrumental in accessing participants from their existing social networks. Additionally, a social network of elders was requested to 
invite the community groups of older women and men, as well as younger women and men, to participate in the study.

Table 1: Overview of the sample of participants (Ebersöhn et al., 2017).

\begin{tabular}{|c|c|c|c|c|c|c|c|c|c|}
\hline Regional & Olde & Older & Younge & Younge & Regiona & Regiona & Regiona & Regiona & Tota \\
\hline case & $\begin{array}{l}\mathrm{r} \\
\text { men }\end{array}$ & $\begin{array}{l}\text { wome } \\
n\end{array}$ & r men & $\begin{array}{l}\mathrm{r} \\
\text { women }\end{array}$ & 1 men & 1 women & 1 elders & 1 youth & 1 \\
\hline $\begin{array}{l}\text { Gauteng } \\
\text { (GP) }\end{array}$ & 16 & 37 & 16 & 26 & 32 & 63 & 53 & 42 & 95 \\
\hline $\begin{array}{l}\text { Swazilan } \\
\text { d (SD) }\end{array}$ & 21 & 29 & 19 & 11 & 40 & 40 & 50 & 30 & 80 \\
\hline $\begin{array}{l}\text { Limpopo } \\
\text { (LP) }\end{array}$ & 16 & 27 & 9 & 31 & 25 & 58 & 43 & 40 & 83 \\
\hline $\begin{array}{l}\text { North } \\
\text { West } \\
(\mathrm{NW})\end{array}$ & 5 & 20 & 3 & 8 & 8 & 28 & 25 & 11 & 36 \\
\hline $\begin{array}{l}\text { Lesotho } \\
\text { (LS) }\end{array}$ & 8 & 6 & 10 & 10 & 18 & 16 & 14 & 20 & 34 \\
\hline $\begin{array}{l}\text { Eastern } \\
\text { Cape } \\
\text { (EC) }\end{array}$ & 5 & 14 & 8 & 12 & 13 & 26 & 19 & 20 & 39 \\
\hline $\begin{array}{l}\text { Namibia } \\
\text { (NM) }\end{array}$ & 7 & 29 & 7 & 20 & 14 & 49 & 36 & 27 & 63 \\
\hline Total & 78 & 162 & 72 & 118 & 150 & 280 & 240 & 190 & 430 \\
\hline
\end{tabular}

Most of the participants (73\%) stated that they currently resided in the region where they had been born.

Figure 1 shows the distribution of the participants' age groups with $41 \%$ of the participants being older women and the majority of the participants falling into the category of 18-30 years old. 


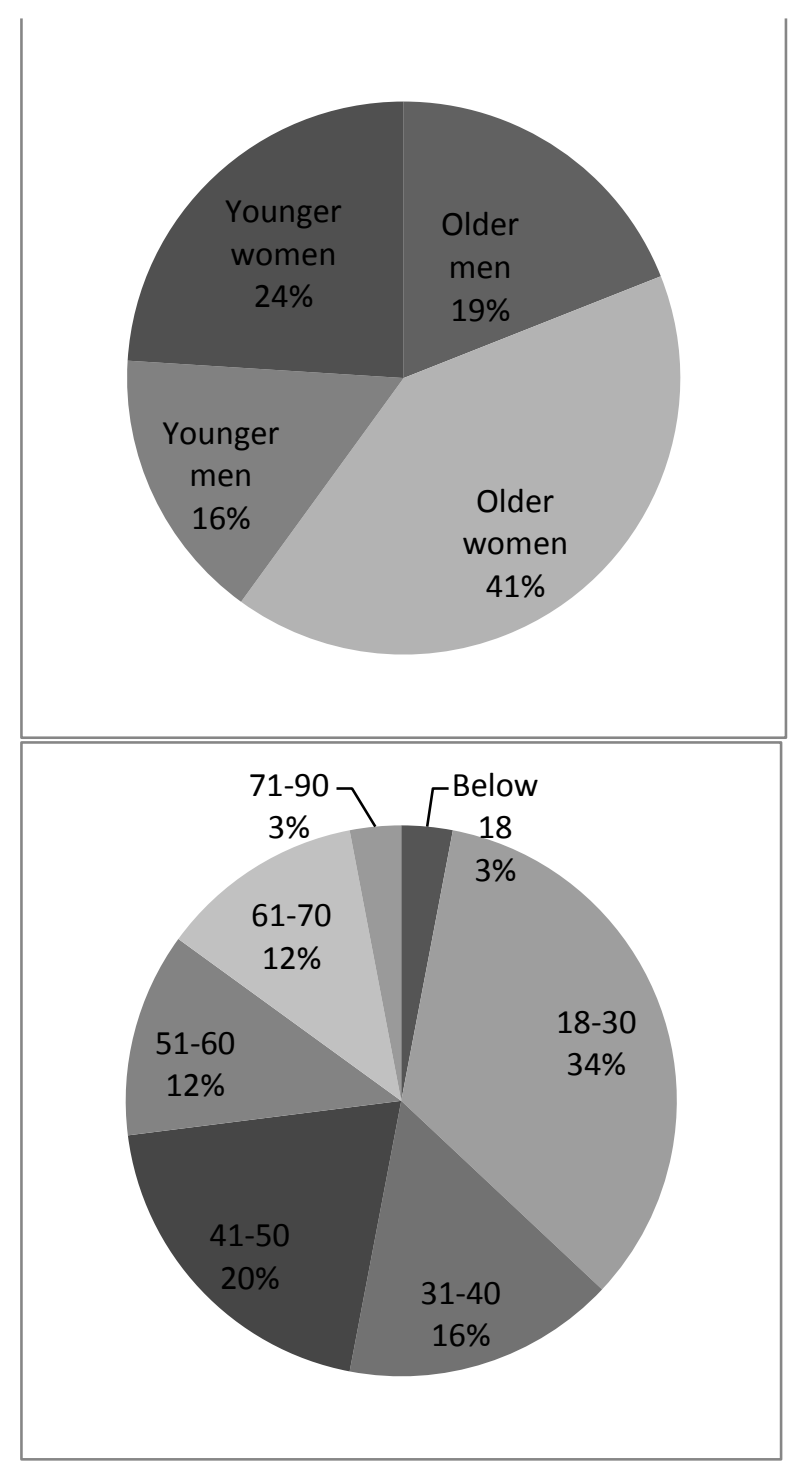

Figure 1: Distribution of age groups among the participants (Ebersöhn, et al., 2017).

The educational level of the participants was low as $20 \%$ had completed primary school or a part of primary school. A further $20 \%$ of the participants reported that they had completed Grades $8-9$, and $16 \%$ of the participants had matriculated from secondary school. Some of the other participants $(23 \%)$ had completed a post-school qualification in the form of either a degree or a diploma. 


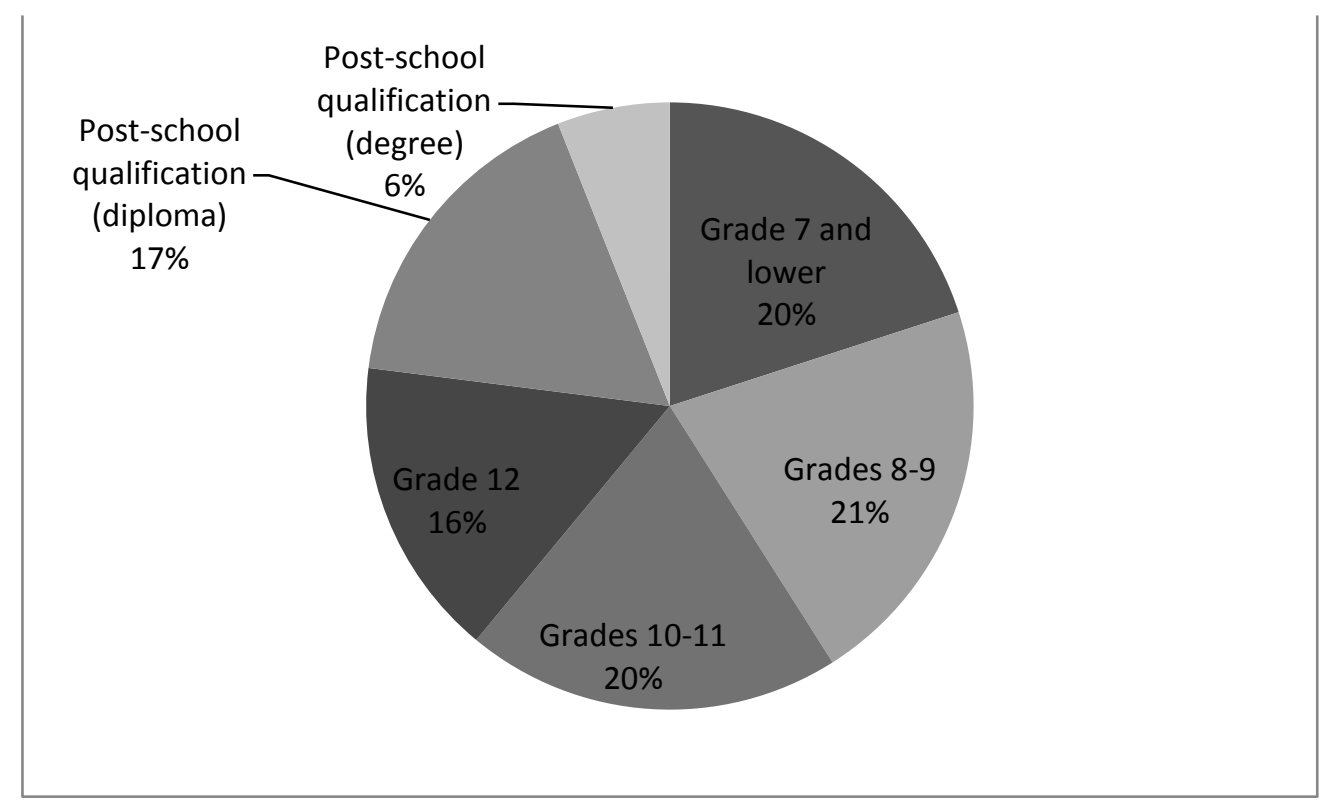

Figure 2: The participants' reported highest level of educational qualification (Ebersöhn, et al., 2017).

In most sites, there were one or two dominant regional languages and English was a parallel dominant language, as $40 \%$ of all participants stated that they spoke English. Multilingualism was evident in Gauteng.

\section{Data collection}

An informed consent form, demographic questionnaire and PRA questions were developed, based on consultation with a reference team, a content expert and regional partners. These were translated and backtranslated into regional languages. Interactive PRA methods were used to generate narratives of indigenous care of and support for people in need (Ebersöhn, 2012). The questions, instructions and aims for the PRA activities used are listed in Table 2 (these focused on various forms of indigenous care and support from a systemic perspective). 
Table 2: The questions, instructions and goals for the PRA activities used (Ebersöhn, et al., 2017).

\begin{tabular}{|c|c|c|}
\hline PRA activity & Questions and instructions & Goals \\
\hline $\begin{array}{l}\text { PRA activity 1: } \\
\text { Care and support of } \\
\text { neighbours/friends in } \\
\text { need }\end{array}$ & $\begin{array}{l}\text { Poster 1: } \\
\text { What would you do traditionally when a neighbour } \\
\text { or friend is in need? You can refer to songs/folk } \\
\text { tales/poems/images that illustrate caring } \\
\text { traditionally for those in need. }\end{array}$ & $\begin{array}{l}\text { IKS knowledge of social } \\
\text { care and support. }\end{array}$ \\
\hline $\begin{array}{l}\text { PRA activity 2: Care } \\
\text { needs of children and } \\
\text { different caregivers } \\
\text { involved }\end{array}$ & $\begin{array}{l}\text { Poster 2: } \\
\text { Write down what children need at which times in } \\
\text { their lives to grow up happy. Use green to draw } \\
\text { circles around the things girls need on the same } \\
\text { poster. Use blue to draw circles around the things } \\
\text { boys need on the same poster. } \\
\text { Poster 3: } \\
\text { Who is responsible for providing all the different } \\
\text { care needs of children and why does this person } \\
\text { play this specific caring role? List all the carers in } \\
\text { a child's life in the left-hand column. Write the } \\
\text { tasks the carers are responsible for in the middle } \\
\text { column. Write the one reason why each carer is } \\
\text { responsible for this caring role/task in the } \\
\text { righthand column. }\end{array}$ & $\begin{array}{l}\text { IKS knowledge of views } \\
\text { related to children's } \\
\text { developmentally } \\
\text { appropriate support and } \\
\text { care together with role } \\
\text { players involved in } \\
\text { caring and supporting } \\
\text { children. }\end{array}$ \\
\hline $\begin{array}{l}\text { PRA activity 3: } \\
\text { Maladaptive traditional } \\
\text { practices }\end{array}$ & $\begin{array}{l}\text { Poster 4: } \\
\text { Share examples of traditional care that are bad or } \\
\text { not good for people. Discuss examples where } \\
\text { traditional care and support is not good for } \\
\text { people's happiness and wellbeing. }\end{array}$ & $\begin{array}{l}\text { IKS on any care and } \\
\text { support practices that } \\
\text { might not benefit } \\
\text { community members } \\
\text { and children. }\end{array}$ \\
\hline
\end{tabular}

Researchers and regional Nelson Mandela Children's Fund partners co-facilitated one day of PRA sessions in the regional language, lasting about 6 hours per site. In cases where there were low literacy levels, the 
participants could opt for co-researchers to assist by reading aloud the items on informed consent and the demographic questionnaires, and then writing down their responses verbatim. PRA activities were conducted in the venues indicated as appropriate by the regional partners and elders. The researchers asked PRA questions (in English) and a regional partner translated the questions in the region's dominant language. Gender- and age-based groups discussed their answers in a PRA-directed group discussion and documented their answers by writing down the groups' answers or by drawing a representative diagram or picture (Chambers, 2013). A representative presented the group's views. These processes were recorded audio-visually, transcribed verbatim, translated and back-translated. Photographs of PRA activities served as visual data. Figure 3 (photographs 1-6) of data generation in Limpopo illustrate the sequence of the PRA data-generation stages at each site.

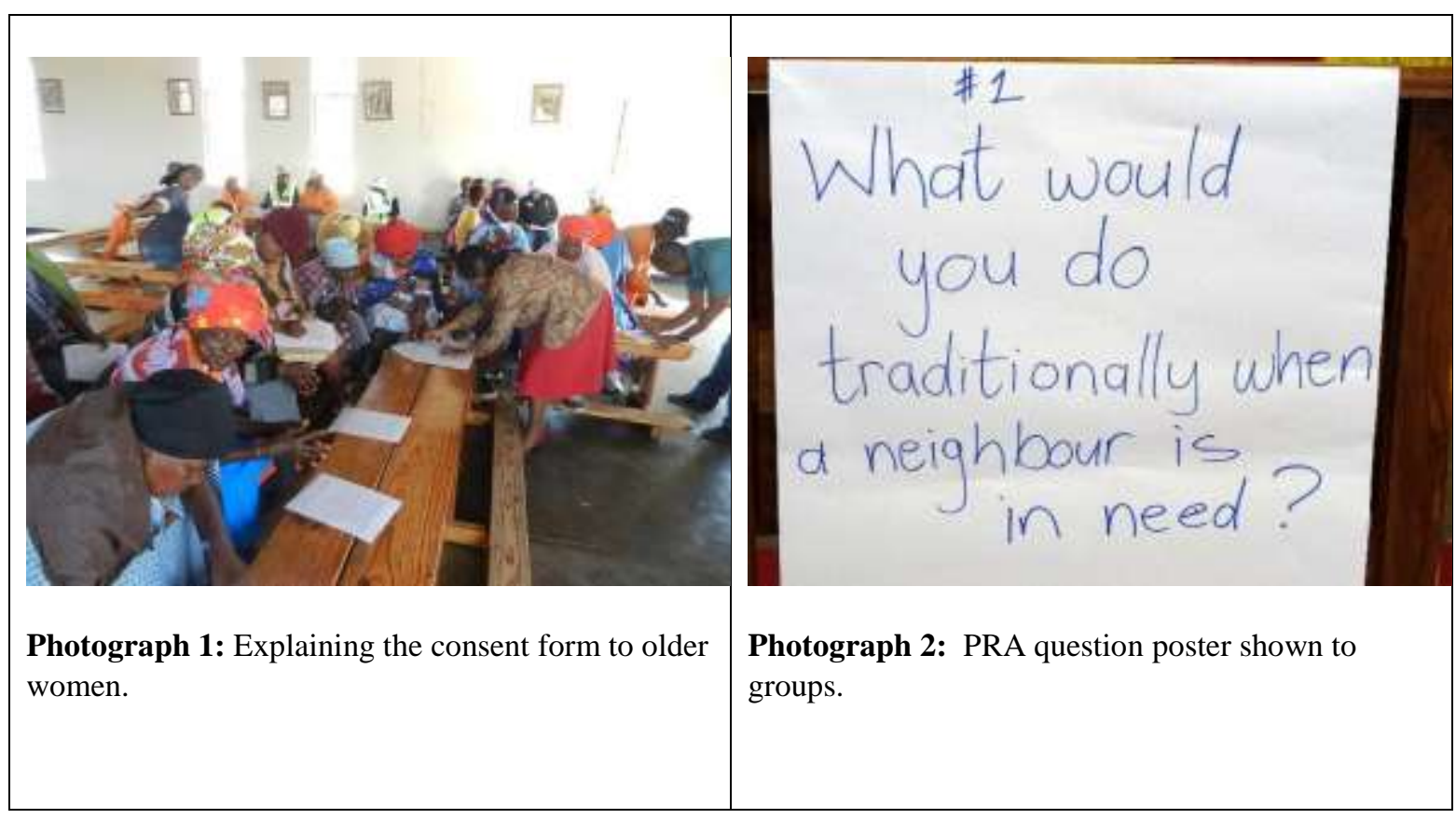




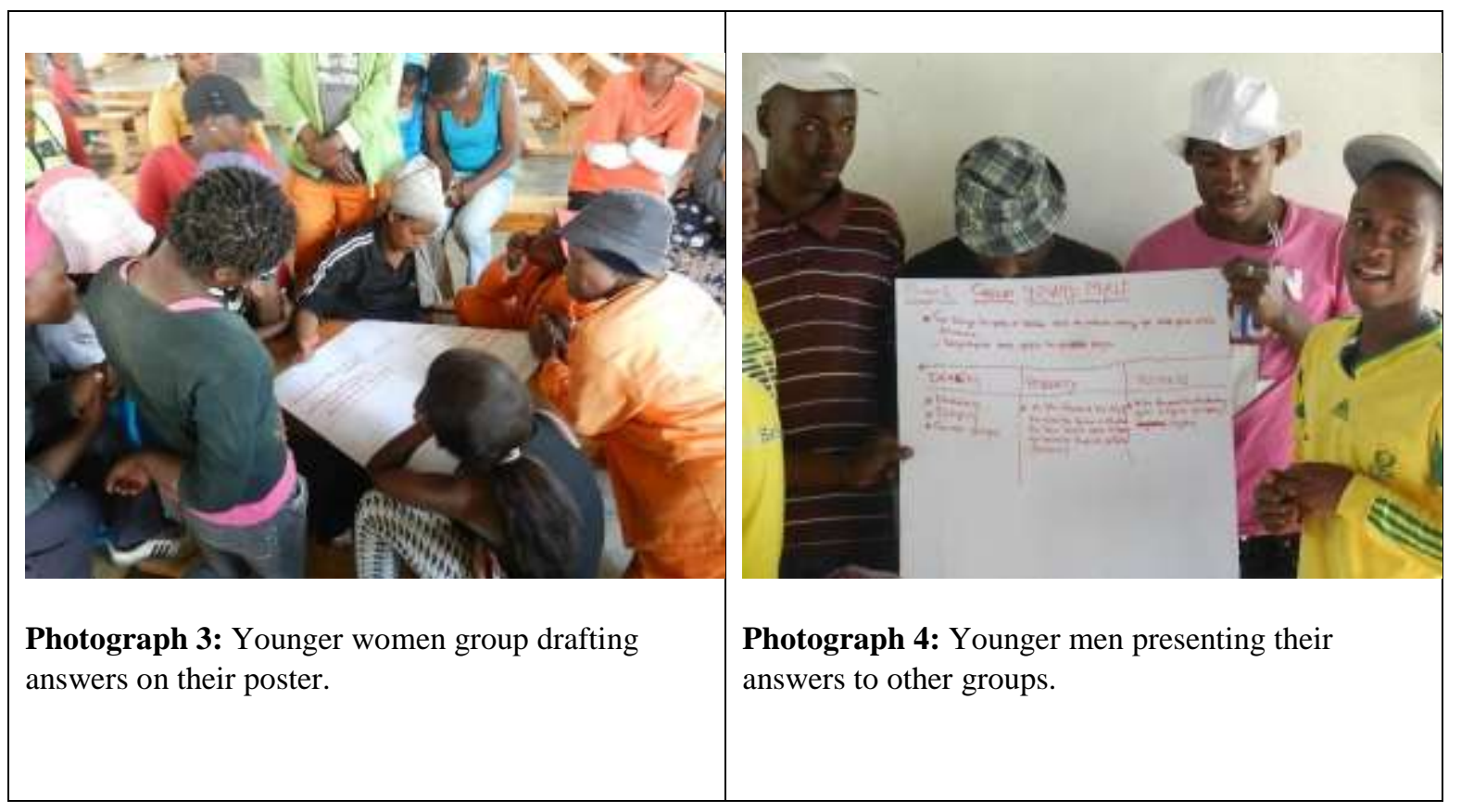

In-case and cross-case analysis

Inductive thematic analysis was used for in-case analysis (Yin, 2013) of transcribed and translated PRA group presentations and visual data (Abedi \& Badregheh, 2011). Cross-case analysis (Silverman, 2013) followed, with the aim of comparing regional cases regarding their African psychosocial support practices. Inclusion criteria for the code "psychosocial care and support" included instances that indicated providing care, support and sympathy to those who were in need in communities.

It became evident that collective resilience responses (flocking) was present in these instances. Where the idea of 'coming together to care and support' was evident themes were subsequently identified to bolster understandings of and describe 'flocking' strategies that support collective resilience.

Triangulation across the data sources, researchers and sites enhanced credibility and authenticity. An audit trail and code-recode strategy during thematic analysis strengthened dependability. Reflexivity during consultation enhanced confirmability.

\section{Ethical considerations}

In alignment with PRA and IKS knowledge generation, the research team consisted of members with both scholarly and place-based expertise, which uniquely positioned them to build rapport with the participants and to co-generate trustworthy data. In line with the University of Pretoria's policy, ethical approval was obtained prior to engagement with the participants. 
An informed-consent letter was translated and checked according to a back-translation procedure and was discussed with the participants. In cases where the researchers were not conversant with a regional language, interpreters co-facilitated the informed-consent process. Participants who could not read or write gave oral consent. As the co-creators of knowledge, the participants were given the opportunity to opt to consent whether they wanted to be identifiable by their names and faces, for data and dissemination purposes.

\section{Results}

\section{Flocking theme of African psychosocial support}

Following thematic analysis, three flocking themes became evident in Southern African psychosocial support. Flocking behaviour was collective, networking and pragmatic. Evidently African psychosocial support was premised on being collective endeavours which connected individuals in similar high-need circumstances with one another by tapping into shared experiences of adapting to challenges; psychosocial support was leverage for collaboration; and psychosocial support favoured pragmatic triedand-tested solutions.

\section{Flocking as a collective space for psychosocial support}

This subtheme describes psychosocial support as collectively coming together (Ebersöhn, 2012), using lived experience to listen to and counsel one another. The theme depicts the belief that "I care for you, and I need to contribute to your wellbeing by helping you find solutions to your problems". The philosophy of "I exist because I belong" reinforces the interdependence that typifies traditional African educational models (Ntuli, 2002). The assumption is that the experience of a neighbour can be used to benefit another (shared knowledge). The theme includes references to the communal connections, neighbourliness and trust that families have built up with their neighbours.

Lived experiences are regarded as essential for psychosocial support, as is captured in the following insert: "And then we give each other advice, for example the father in the house is fighting. When you intervene as a neighbour, you listen and establish who started the fight and where the problem started. This is where you sit down the parents of that household and assist them in the way that you can help them" (GP-OW, 39-45). The care and support provided by the neighbours in the above case involved building the 
family, helping the couple to find meaning in their adverse experiences and communicating their differences. Collaborative problem solving is demonstrated as connectedness between neighbours and trust in the counsel provided, which is supported by the following remark of an older woman from Gauteng: "My neighbour and I explained what happened and my neighbour helped me to resolve this problem" (GP-OW, 105-106). The connectedness between neighbours is evident in the way they found support and preserved strong bonds with the community in which they live. One participant explains their unity as follows: "If we are united, we have more than one set of hands" (NWOW, 38-39).

Participants reflected on caring for each other during times of need: "Even if you and your neighbour had quarrels and fights when death is there it (fight) is forgotten; there it is cleared, there you go to your neighbour's house and you make that death your problem" (NM-OW, 126-128); We come to assist, make tea, we come to console our neighbor during this period. When she has problems in these times that we are living in... you assist in the way that you can assist" (GP-OW 26-31).

The reported unity and connectedness amongst neighbours were also evident in the way they assisted each other with child rearing practices: "So here your neighbors child is your child, when you see the child doing something that is not in order on the streets you must not just pass them and do nothing and say they are not your child so why should you help them" (GP-OW, 48-52); "They would meet a problematic child in the neighbourhood they would treat that child as their own child beat that child as they own child and that's how they helped each other to discipline children in their communities" (NM-OW, $170-172)$

The principle of a collective space for psychosocial support is in line with the expression Eniyan l'aso which is a Yoruba proverb, and literally means that the people (family, relatives, friends, community) around you function like the clothes on your back: the clothes protect you, cover your nakedness (your secret is our secret), shield you from the weather, and beautify you (Yoruba proverb, personal communication, 2015). In indigenous communities, care and support for one another form the core of relationships. In many African communities, caring for the sick and vulnerable involves a whole process of both physical and spiritual domains, which is often in contrast to Westernised concepts of care and support (Memela \& Makhaba, 2013). 


\section{Flocking capitalises on networking}

Another psychosocial support premise was to use social capital to network during problem-solving, especially to buffer against financial insecurity. Psychosocial support includes networking as a problemsolving strategy which encourages communal support and promotes caring and contributing to one another's success (Ntuli, 2002): “ “.. when see my neighbour has lost employment we search for work. It's like that (...) when one of us is unemployed. (...) It's better that I encourage her to join me and look for a job" (EC-YW, 93-96). Participants explained: "Everyone will put in something everyone will look where she or he can help even if you don't have money you will look around how to clean" (NM-OW, 129-131). More often than not, sharing what you have available was related to providing food to households at-risk: "In hunger you can share with them the little that you have. Whether it being food, or if you have a bit more, you can share with them” (NW-YW, 134-135); “...you take what you have and give it to a person or house that is affected by hunger" (EC-OW, 26-27); "What we do is people will bring whatever they have and we give to the family. One would bring tinned fish, another one tinned corned beef' (LP-YW, 67-69); and "If the neighbour has no ploughing means, the neighbours come together and make contributions to make it possible for him to plough plant and have something to eat for his family" (SD-OW, 64-67).

Psychosocial support also tapped into the organisations formed by a community of people to serve a particular purpose of support (a society, stokvel). Nsamenang (1996) and Zimba (2002) similarly report on the sharing of resources. Societies govern psychosocial support strategies by accruing volunteered resources which they disburse for the mutual benefit of members in a particular community. This includes physical (providing services) and financial support. Membership is drawn and rules are enforced where representatives are selected to serve in particular roles. The main purpose of societies is to collate resources (mostly money) and save it for future adversities such as death, or for celebrations such as weddings (ARC, 2009). The purpose is to help one another by amassing resources for the sustenance and preservation of the community's resources. A group of older women from Lesotho remarked in this regard: "Then we make a small group as older women and form a society of R5s" (LS-OW, 72-73).

Being part of a society offers security and also serves as insurance that costs will be covered when a member is most vulnerable: "Again, another basic thing is that, when one is unemployed, my friend or neighbour is unemployed, (...) there are many societies, those that many people can find livelihood from. $\mathrm{He} / \mathrm{she}$ can join that society which collects some contributions and keeps it so that when the year ends 
he/she can get some dividends to feed them” (LS- YM, 200-206). Another participant explains: “...Because I see that he or she is in need, I will say: take this money and see what sustainable project you can start with it” (LS-YM, 186-190).

Gender roles in networking for psychosocial support were emphasised by the group of older women in the Eastern Cape: "We go collectively as neighbours and convene. We do have women in our community that are active in their organisations. It's like this and that in that particular household. What do we do? (...) Let's go out and meet with others and collect /gather whatever we can get. We approach undertakers (vantyi). We even go to local businesses. We have this shop in our neighbourhood. We usually involve him and share the problem. He will give us contribution to meet us halfway. That is what we do as neighbours" (EC-OW, 48-55). Networking and collaboration were used to form alliances.

Using networking to link acquaintances with available job opportunities was evident: “... we could look out for employment with him or her. (...) our neighbour or friend doesn't know everywhere there is a vacancy" (LS-YM, 164-167); "You can even speak to people or employers on his behalf so that he can get a job. You can help them when they are in trouble. When they are unemployed, that is when you offer your help the most" (NW-YW, 127-130).

\section{Flocking is pragmatic}

Pragmatically, those in distress were encouraged by recommending practical solutions to address a problem, be it for matters of livelihood or for health care. A robust example of pragmatism in psychosocial support is that of "smart partnerships", as explained by the group of older men in Lesotho: "We now form a smart partnership with such a person. A smart partnership with such a person is to share agriculture" (LS-OM, 57).

Pragmatism is also evident in other examples of smart partnership. The group of participating young men in Lesotho encouraged self-help projects such as producing vegetables for a person who had lost a job: "In this case the family will be encouraged to plough vegetables and in some instances they will be given mealie-meal and beans" (LS-YM, 6-9). Another smart partnership is that of joining existing entrepreneurial projects to promote that financial independence: "We would advise them on the point of projects (...) like chicken rearing. (...) we could help her to go there (the chicken farm) to wash some chickens (...) even give her some money to start her own business" (LS-YM, 256-261). 
The participating group of older women in Namibia was pragmatic about providing health support to children: "....we talk to our kids, ... encourage them to go to the hospital or to the clinic for blood tests and for counselling" (NM- OW, 72-74). Younger women indicated: "In the case of illness, we collect medication from hospitals/clinics on behalf of the sick" (LP-YW, 60-61); "When my neighbour is sick... I took him to clinic I check his clinic book and check when last he visited the clinic, maybe he is sick he last visited the clinic last year when we visit there they will check and give her a right date, check if he takes proper medication and haven't defaulted his medication before sickness overpowers him" (ECYW, 106$113)$.

Pragmatism was also used for giving advice in instances of abuse, by suggesting relevant protection from the law: "So if my neighbour is being abused, we support them and tell them that neighbour let's go to the police station and tell the police that this person is abusing you" (GP-YW, 183186). The participating older women in Namibia were similarly pragmatic: "We (...) talk to our friend to see the social worker (or the) psychologists" (NM-OW, 80-81). The older women in Namibia provided pragmatic motivation to support people who were ill: “Okay but why don't you try this medication, why don't we go to a traditional healer somewhere or come let's go to the hospital" (NM-OW, 146-148).

The older female respondents in Namibia referred to the pragmatic advice that they would offer to adolescent girls: “...the late minister always told people 'let your boyfriend be your book and if your boyfriend is your book you will never fall pregnant until you finish what you want to achieve'. That's how I grew up.” (NM-OW, 219-221). In Ntuli’s (2002) review of indigenous knowledge systems, he also refers to the amaqhikiza system, a type of mentorship programme where older girls mentored younger girls. In these types of educational programmes, group learning and group solutions for group problems were the norm.

\section{Discussion}

We found that the findings from seven challenging contexts in four Southern African countries could in general supplement the dominant Western discourses on psychosocial support. In particular, we found IKS evidence of the principles that underpin Southern African psychosocial support. Southern African psychosocial support manifests as social innovations which are collective, networking and pragmatic. 
This has implications for interventions aimed at providing psychosocial support in transferable contexts. Such interventions could be strengthened by acknowledging that, from a collectivism perspective, the beneficiaries of support believe that they have resources to contribute to support strategies - even given their resource constraints. Similarly, beneficiaries have access to meaningful social capital to mobilise as networks in delivering social support and buffering against ongoing challenges. In addition, interventionists may expect to find pragmatic and wise partnerships on which additional support could be built.

There was evidence of flocking among the participating groups of older and younger women and men in the seven conveniently sampled Southern African communities with high need and indigenous belief systems. Consequently the findings support the generative theory of Relationship-Resourced Resilience (RRR) as a Southern African response to adversity. We found evidence that flocking constitutes pragmatic collective resilience responses, which is understandable given the ecological constraints in a postcolonial, where citizens had limited access to formal governance structures for policy decisions about resources and services.

Our findings suggest that in the face of adversity and the lack of access to and provision of formal wellbeing services, the participants seemed able to establish and provide their own services relating to psychosocial care and support. The existing practices of African psychosocial support, without outsider investment, were evident across all the participants in Southern Africa. The participants mobilised their indigenous knowledge, skills and practices to respond actively and collectively to chronic risk in their communities. The mobilisation of social capital was evident, including the element identified by Kuku and colleagues (2013): social resources such as informal arrangements among neighbours or in the community; collective resources including the formulation of self-help groups, credit unions and community safety schemes; economic resources which would be based on the levels of employment and access to green, open spaces for cattle and cultural resources. Pelling (2003: 67) refers to this as the concept of adaptive potential, in essence describing the actions that employ "social and political assets to enhance local resilience". For instance, letsema [a work party] (Mofuoa: 2014), is a social capital or practice central to Basotho's ways of garnering social resources. It is also political in that for the local chiefs, all people are obliged to take part in work that is for the benefit of the one ruling. The chief in turn is expected to take care of the widows or orphans in his village with the proceeds of the letsema where everybody participated, such as providing 
maize for feeding after the people worked in the chief's fields. The chief can also organise a letsema for projects which will benefit the community, and it is politically correct for everyone to contribute.

Long-standing and collective care was evident in the way in which the participants actively responded to psychosocial needs by collectively investing in continued insider-driven care. The participants reflected on being pragmatic about capitalising on social capital and using networks and smart partnerships in solving problems and finding solutions to challenges. Woods and colleagues (2011) concur that this includes sharing, contributing and investing collective capital, in terms of both the available resources and the identified needs.

The findings of this study are delimited to transferable contexts. The transferability of findings is contingent on cognisance that Lesotho and two South African provinces (North West and the Eastern Cape) were underrepresented in the snowball sampling of the participants.

Given that both older and younger men were less represented, it would be significant to explore the extent to which the findings are gender-biased. Plausibly, more male participation could have included diverse views on psychosocial support from an IKS perspective. This merits further investigation.

Most of the participants (73\%) indicated that they continued to reside in the region where they had been born. It may therefore merit investigation to determine the extent to which IKS remains robust, or has adapted, given urbanisation and globalisation. Some additional comparative analysis of similarities and differences in the rural and the two urban sites (Gauteng and Namibia) may provide some hypotheses for further studies in this regard.

Besides a bias towards female perspectives on IKS in psychosocial support, the sample also shows an age bias in the range of 18-30 years of age. It seems as if relatively young people continue to use indigenous knowledge in their care practices. Studies with different age demographics may provide added insights into the manner in which IKS is used across the generations in Southern Africa.

Given the low levels of education in the sample (where $20 \%$ had completed primary school or a part of primary school), it may be prudent to conduct studies on the impact of educational level on IKS in psychosocial support. 


\section{Conclusion and recommendations}

The presence of flocking as a response to adversity is bolstered by evidence amongst elders and young people in challenged settings in other Southern African countries (Namibia, Lesotho and Swaziland), and South African provinces (De Gouveia, 2015; Malan-van Rooyen, 2015; Ebersöhn, Sefotho, Mampane, Loots, Omidire, Sherman \& Nxumalo-Tsebe, 2014). Findings from this study therefore augment flocking, in the indigenous psychology theory RRR (Ebersöhn, 2012, 2013) as a collective resilience response that is Southern African (used beyond three South African provinces), exists despite intervention research, and is prevalent amongst non-Western, Southern African elders and young people other than teachers. In addition evidence of flocking is expanded by findings of how collective resilience manifests to provide psychosocial support, i.e. flocking is collective, pragmatic and capitalises on networking.

A key recommendation is that outside interventions should not be developed around episodic and individual needs. Rather, we recommend that outside investors who focus on the provision of psychosocial support, should build interventions around the existing traditional psychosocial practices of care and support that are already in place. Outside investors could capitalise on flocking as pathway to support. In order to collectively investing in continued insider-driven growth development initiatives can capitalise on the promise of leveraging collective space, networking and pragmatic care and support to respond to psychosocial needs.. Outside assistance could graft on to these existing structures of psychosocial support.

Intervention-related investment therefore ought to support and reward the existing African psychosocial support principles. Investment strategies should target collective responses to need, rather than give funds to individuals identified as being in need. The aim is to steer clear of passive dependence, and to reward (and graft onto) collective agency. Outsider investors could request documented examples of the mutually beneficial use of investment, as well as the strategies for monitoring and evaluation that are currently in place, to assess the progress made towards mutual benefit and absence of dependence on outsider support.

This study provides evidence by Southern African beneficiaries of psychosocial support of knowledge relevant to services to them - rather than paternalistic ideas of what matters from an outsider's perspective. In this way, the insights of Southern African indigenous responses into adversity could inform psychosocial interventions in settings with predominantly African populations. 


\section{References}

Abedi, M., \& Badragheh, A. (2011). Participatory rural appraisal (PRA): New method for rural research. Journal of American Science, 7(4), 363-368.

African Development Bank Group. (2011). African Development Report: Private sector development as an engine of Africa's economic development.

Allwood, C.M., \& Berry, J.W. (2006). Origins and development of indigenous psychologies: An international analysis. International Journal of Psychology, 41 (Special issue), 243-268.

ARC. (2009). Psychosocial Support, ARC Resource Pack: ARC ModF7 Study Material 2009 http://www.arconline.org.

Bassett H, Lloyd C and Tse S (2008) Approaching in the right spirit: Spirituality and hope in recovery from mental health problems. International Journal of Therapy \& Rehabilitation 15(6), 254-261.

Bongani, M., Mayosi, B.M., \& Benatar, S.R. (2014). Health and health care in South Africa - 20 years after Mandela. New England Journal of Medicine, 371(14), 1344-1353.

Briggs, J. (2005). The use of indigenous knowledge in development: problems and challenges. Progress in Development Studies, 5(2), 99-114.

Bunkers, K., \& Andrews, S. (2017). Case study on case management for children orphaned and made vulnerable by HIV (OVC): Building a user-friendly and government-owned case management system for highly vulnerable children. The Yekokeb Berhan Program Experience in Ethiopia. PEPFAR, USAID \& 4Children: Catholic Relief Services http://ovcsupport.org/wpcontent/uploads/2017/06/4Children_YBEthiopia_17OS079_FINAL_rev $\underline{1 . p d f}$

Chambers, R. (2013). From rapid to reflective: 25 years of Participatory Learning and Action. In H. Ashley, N. Kenton, \& A. Milligan (Eds.), 66 Participatory learning and action tools for supporting sustainable natural resource management and livelihoods (pp. 12-14). London: The International Institute for Environment and Development (IIED).

Chilisa, B. (2012). Indigenous research methodologies. Thousand Oaks, CA: SAGE Publications.

Chochinov, H.M., \& Cann, B.J. (2005). Interventions to enhance the spiritual aspects of dying. Journal of Palliative Medicine, 8 (supplement 1), s-103.

De Gouveia, J. (2015). Indigenous pathways to well-being as resilience outcome in rural communities. 
Unpublished PhD Thesis. Pretoria: University of Pretoria.

Eaton, J., McCay, L., Semrau, M. et al. (2011). Scale up of services for mental health in low-income and middle-income countries. The Lancet, 378(9802), 1592-1603.

Ebersöhn, L. (2012). Imagining career resilience research and training from an indigenous knowledge production perspective. South African Journal of Higher Education, 26(4), 800-812.

Ebersöhn L (2012) Adding 'Flock' to 'Fight and Flight' as Responses to Persistent Adversity: A Honeycomb of Resilience where Supply of Relationships meets Demand for Support. Journal of Psychology in Africa 22(1): 29-42.

Ebersöhn L (2013) Building generative theory from case work: The relationship-resourced resilience model. In: Wissing MP (ed.) Wellbeing research in South Africa. New York: Springer, pp. 97122.

Ebersöhn, L. (2016). Keynote Address: Education research in challenging contexts: resilience and cultural capital as a vision for sustainable development in Africa. International Conference on Education Research for Development in Africa (ICERDA) 2016. 3-5 October 2016, Alisa Hotel, Accra, Ghana.

Ebersöhn L, Sefotho M, Mampane, R. et al. (2014). Imbeleko and social connectedness. Pretoria: Nelson Mandela Children's Fund.

Ebersöhn, L., Loots, T., Mampane, R. et al. (2017). Age-old care and support practices in Southern Africa functioning robustly as sophisticated social technology interventions. Journal of Community Psychology, 45(6), 727-747.

Eggenberger, N. (2012). Research on psychosocial support: A journey into uncharted territory. Presentation-Novartis Foundation for Sustainable Development Symposium, December 4.

Gone, J.P. (2010). Psychotherapy and traditional healing for American Indians: Exploring the prospects for therapeutic integration. The Counseling Psychologist, 38(2), 166-235.

Hanlon, C., Luitel, N., Kathree, T. et al. (2014). Challenges and opportunities for implementing integrated mental health care: a district level situation analysis from five low- and middleincome countries. PLoS One, 9(2), e88437.

Harding, R., \& Higginson, I.J. (2005) Palliative care in sub-Saharan Africa. The Lancet, 365(9475), 19711977.

Hlalele, D. (2012). Psychosocial support for vulnerable rural school learners: In search of social justice. Journal of New Generation Sciences, 10(2), 67-73. 
Johnson, O.D., (2012). Toward a Theory of Place. Social Mobility, Proximity and Proximal Capital. In W.F. Tate (Ed.), Research on schools, neighborhoods, and communities: Toward civic responsibility (pp.29-46). Maryland: Rowman \& Littlefield.

Kayombo, E.J., Mbwambo, Z.H., \& Massila, M. (2005). Role of traditional healers in psychosocial support in caring for the orphans: A case of Dar es Salaam City, Tanzania. Journal of Ethnobiology and Ethnomedicine, 1(1), 1.

Khan, S., \& Van Wynsberghe, R. (2008). Cultivating the under-mined: Cross-case analysis as knowledge mobilization. Forum: Qualitative Social Research, 9(1), Art. 34.

Kim, U. (2000). Indigenous, cultural and cross-cultural psychology: A theoretical, conceptual, and epistemological analysis. Asian Journal of Social Psychology, 3(3), 265-287. doi: 10.1111/1467839X.00068

Kuku, A.A., Omonona, B.T, Oluwatayo, I.B., Ogunleye, O.O. (2013) Social capital and welfare among farming households in Ekiti State. Journal of Biology, Agriculture and Healthcare, 3(5), 115130.

Malan-van Rooyen, M. (2015). Indigenous pathways to adaptive coping in rural communities. Unpublished PhD Thesis. Pretoria: University of Pretoria.

Maree. K., Ebersöhn, L., \& Molepo, M. (2006). Administering narrative career counselling in a diverse setting: trimming the sails to the wind. South African Journal of Education, 26(1), 49-60.

Marsella, S.C., \& Gratch, J. (2009). EMA: A process model of appraisal dynamics. Cognitive Systems Research, 10(1), 70-90.

Masango, M.J. (2005). The African concept of caring for life. HTS Theological Studies/Teologiese Studies, 61(3), 915-925.

Matoane, M. (2012). Locating Context in Counselling: The Development of Indigenous Psychology in South Africa. Psychotherapy and Politics International, 10(2), 105-115.

Memela, N.C., \& Makhaba, V.L. (2013). Culture as anchor or culture as impediment? The plight of Child Care Workers (CCWs) in dealing with HIV related deaths in a children's home. Indilinga: African Journal of Indigenous Knowledge Systems, 12(1), 80-95.

Mofuoa, K. (2014). "Applying Ubuntu-Botho African ethics to stakeholder corporate social responsibility." Management Research: The Journal of the Iberoamerican Academy of Management, 12(3), 222-239.

Ebersöhn, L., Sefotho, M., Mampane, R., Loots, T., Omidire, F., Sherman, V., \& Nxumalo-Tsebe, T. 
(2014). Imbeleko Report: Cultivating resourcefulness, not dependency. Pretoria: Nelson

Mandela Children's Fund \& University of Pretoria.

Ntuli, P.P. (2002). Indigenous knowledge systems and the African renaissance. Laying a foundation for the creation of counter-hegemonic discourses. In C.A. Odora Hoppers (Ed.), Indigenous knowledge and the integration of indigenous knowledge systems: Towards a philosophy of Articulation (pp. 53-66). Claremont: New Africa Books.

Odendaal, N.D., \& Moletsane. M., (2011). Use of indigenous stone play in child psychological assessment. Journal of Psychology in Africa, 21(4), 623-626. doi: 10.1080/14330237.2011. 10820510

Odora Hoppers, C.A. (2008). Culture, language, indigenous knowledge and the role of universities in sustainable rural development. Paper presented at the Conference of the Centre for Education Policy Development (CEPD). Johannesburg, South Africa.

Owusu-Ansah, F.E., \& Mji, G. (2013). African indigenous knowledge and research. African Journal of Disability 2(1): Art. \#30 5 pages. Retrieved from: http://dx.doi.org/10.4102/ajod.v2i1.30

Pelling, M. (2003). The vulnerability of cities: Natural disasters and social resilience. Earthscan.

Petersen, I., Bhana, A., Campbell-Hall, V., Mjadu, S., Lund, C., Kleintjies, S., Hosegood, V., \& Flisher, A.J. (2009). Planning for district mental health services in South Africa: a situational analysis of a rural district site. Health Policy Plan, 24(2), 140-150.

Petersen, I., Bhana, N., Myeza, N., Alicea, S., John, S., Holst, H., McKay, M., \& Mellins, C. (2010). Psychosocial challenges and protective influences for socio-emotional coping of HIV+ adolescents in South Africa: A qualitative investigation. Aids Care, 22(8), 970-978.

Pickren, W. E. (2009). Indigenization and the history of psychology. Psychological Studies, 54(2), 87-95.

Reblin, M., \& Uchino, B.N. (2008). Social and emotional support and its implication for health. Current Opinion in Psychiatry, 21(2), 201-205.

Rosenberg, A., Hartwig, K., \& Merson, M. (2008). Government-NGO collaboration and sustainability of orphans and vulnerable children projects in southern Africa. Evaluation and Program Planning, 31(1), 51-60.

SADC. (2010). Regional Conceptual Framework for Psychosocial Support for Orphans and Vulnerable Children and Youth. 11 October 2010, 4th Draft.

Schmidt, N.B., Richey, J.A., Zvolensky, M.J., \& Maner, J.K. (2008). Exploring human freeze responses to a threat stressor. Journal of Behavior Therapy and Experimental Psychiatry, 39(3), 292- 304. 
Silverman, D. (2013). Doing qualitative research (4 $4^{\text {th }}$ ed.) Thousand Oaks, CA: SAGE Publications. United Nations. (2015). The millennium development goals report 2015. New York: United Nations. Vanderbilt, A. A., Isringhausen, K. T., VanderWielen, L. M., Wright, M. S., Slashcheva, L. D., \& Madden, M. A. (2013). Health disparities among highly vulnerable populations in the United States: a call to action for medical and oral health care. Medical Education Online, 18(1), 20644. DOI: 10.3402/meo.v18i0.20644; http://dx.doi.org/10.3402/meo.v18i0.20644

Walsh, F. (2015). Strengthening family resilience ( $3^{\text {rd }}$ ed.). New York: Guilford Publications.

Westerman, T. (2010). Engaging Australian aboriginal youth in mental health services. Australian Psychologist, 45(3), 212-222.

Woods, A.M., Linley, P.A., Maltby, J., Kashdan, T.B., \& Hurling, R. (2011). Using personal and psychological strengths leads to increases in well-being over time: A longitudinal study and the development of the strengths use questionnaire. Personality and Individual Differences, 50(1), 1519.

World Health Organisation. (2006). Basic Documents, Forty-fifth edition, Supplement, October 2006.

Yin, R.K. (2013). Case study research: Design and methods ( $5^{\text {th }}$ ed.) Thousand Oaks, CA: SAGE Publications.

Zartman, I.W. (2012). Comparative Case Studies. In D.J. Christie (Ed.), The Encyclopaedia of Peace Psychology (pp.1-4). Blackwell Publishing Ltd. DOI: 10.1002/9780470672532.wbepp043.

Zimba, R.F. (2002). Indigenous conceptions of childhood development and social realities in Southern Africa. In H. Keller, Y. Poortinga, \& A. Schölmerich (Eds.), Between Biology and Culture: Perspectives on Ontogenetic Development. Cambridge: Cambridge University Press. 